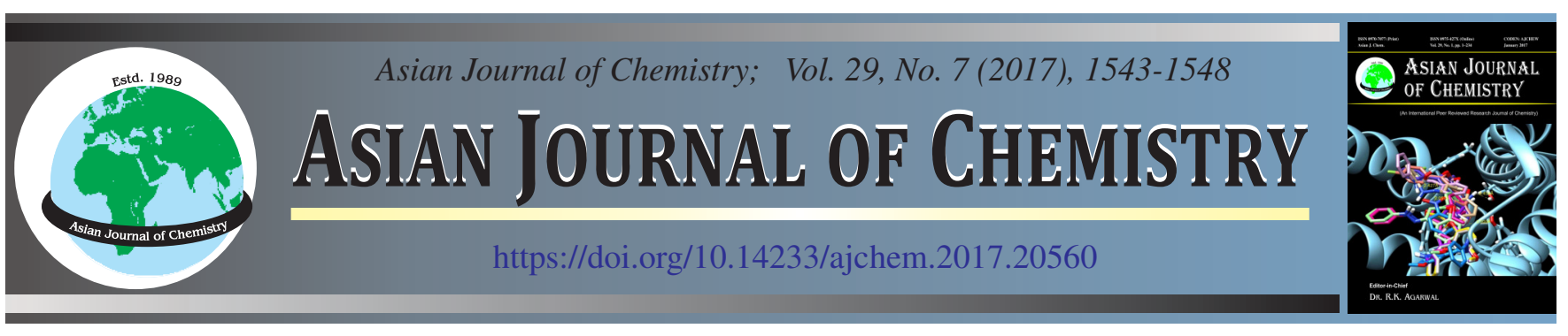

\title{
Macadamia integrifolia: A New Source of Natural Dyes for Textile Colouration
}

\author{
Md. Ahsan Habib ${ }^{1, *}$, Md. Nahid Pervez ${ }^{1,2}$, Sakil Mahmud $^{1}$, Meer Md. Rasel Khan ${ }^{1}$ and Quan Heng ${ }^{1}$
}

${ }^{1}$ School of Chemistry \& Chemical Engineering, Wuhan Textile University, 430073, P.R. China

${ }^{2}$ Research Institute of Flexible Materials, School of Textiles \& Design, Heriot-Watt University, Galashiels TD1 3HF, UK

*Corresponding author: E-mail: ahsanhabib@qq.com

Received: 1 February 2017

Accepted: 28 March 2017;

Published online: 13 May 2017;

AJC-18390

\begin{abstract}
In this research, an attempt has been made to extract natural dye from Macadamia integrifolia, as a new source for cotton dyeing with good enough properties for potential commercial applications. Optimum extractions were observed with a sodium hydroxide as solvent at $60{ }^{\circ} \mathrm{C}$, time $60 \mathrm{~min}$ and $\mathrm{M}: \mathrm{L}$ was $1: 20$. The study of different factors effecting dyeability of cotton fabrics were acquired at following conditions: dye concentration $50 \%$, salt concentration $10 \mathrm{~g} / \mathrm{L}, \mathrm{pH} 8,85^{\circ} \mathrm{C}$ and $120 \mathrm{~min}$. The colour strength $(\mathrm{K} / \mathrm{S})$ and fastness properties were found to be satisfactory in the post-mordant-processed fabric with the use of optimum mordant $(\mathrm{M} 1>\mathrm{M} 3>\mathrm{M} 2)$ concentration of $3 \%$. Based on UV-visible spectra analysis, presence of lignin was confirmed on extract of aqueous Macadamia integrifolia. The chemical composition analysis was determined by Fourier transform infrared spectroscopy (FT-IR) and surface morphology of cotton fibers were investigated by scanning electron microscopy (SEM) for any changes on fiber. It is hoped that with analytical assay natural colourants can be tailored to access acrimonious functional ambit of synthetic dyes for the textile industries up to some extent, especially in case of the natural fibers colouration.
\end{abstract}

Keywords: Macadamia integrifolia, Lignin, Post-mordant, Colour fastness.

\section{INTRODUCTION}

The acquaintance of ecology abuse associated with processing and absolution of synthetic dyes, has been led to animate a new appeal in dyeing with natural extracted dyes and today it is arising globally due to the actuality that they are safer and added environment-friendly [1]. As a result, the appliance of natural dyes is considered as a better alternative to synthetic dyes. This is a after effect of the acrimonious ecology standards imposed by abounding countries in acknowledgment to the baneful and allergic reactions associated with synthetic dyes. They exhibit high biodegradability, low toxicity, green chemistry and have the potential to greatly impact the textile industry which is considered as one of the communicable industry today [2-5]. Recent research in the natural dye breadth accept articular them as a typical agents in imparting multifunctional properties to textiles such as antimicrobial, insect repellent, deodorizing and UV-protection [6,7]. In animosity of several advantages of natural dyes over the synthetics, the use of the above is still actual bound due to non-availability of standard shade cards and accepted appliance procedures. Most of the natural dyes have no substantivity for the fibre and are appropriate to be acclimated in affiliation with mordants. A mordant, usually a metallic salt, is regarded as a chemical, which can itself be fixed on the fibre and also combines with the dyestuff. A link is formed between the fibre and the dye, which allows certain dyes with no or little affinity for the fibre to be fixed [8]. Macadamia integrifolia, as well called Macadamia nut, Queensland nut and Australian nut, is a species of flowering plants in the family Proteaceae. It is built-in to southeastern Queensland area it grows in the rain forests. The outer skin of Macadamia integrifolia is green, while the endocarp is brown and relatively thick, the kernel is smooth and delicately delicious, which has a unique cream fragrance and enjoys the name of "the queen of nut". Macadamia integrifolia is a high energy food and contains no cholesterol. The main composition of macadamia nutshell is lignin $(47 \%)$, cellulose $(25 \%)$, hemicelluloses (11\%) and ash (0-2\%) [9,10]. Considerable research work is being undertaken around the world on the application of natural dyes [11-15]. However, based on the author's knowledge there is no work reported in the literature on the use of macademia nut as a natural dye in textile applications.

Various national and international institutes accept been affianced in extracting colours from natural sources and efforts are still being made by researchers to overcome various drawbacks of natural dyes such as poor reproducibility and lack of desirable fastness properties [16]. This work is concerned with the extraction of dye from macademia nut and its appliance 
on affection fibre in an endeavour to investigate optimal extraction and appliance altitude to attain desirable fastness properties.

\section{EXPERIMENTAL}

Plain weaved bleached cotton fabric $\left(240 \mathrm{~g} \mathrm{~m}^{-2}\right)$ was procured commercially and used for throughout this research. Alum, zinc sulphate and manganese sulphate were used for mordanting processes. Macadamia integrifolia nutshells were purchased from local market. Then washed out thoroughly and dried in the sun and grounded to powder form.

Optimization of extraction conditions: Various trials were carried out to optimize extraction parameters such as solvent, temperature, time and M:L ratio. Extraction was done in Soxhlet apparatus at different temperatures $(30,40,50,60$, $\left.70{ }^{\circ} \mathrm{C}\right)$ and different time $(30,40,50,60,70 \mathrm{~min})$, different $\mathrm{M}: \mathrm{L}$ ratio $(\mathrm{A} 1=1: 10, \mathrm{~A} 2=1: 20, \mathrm{~A} 3=1: 30, \mathrm{~A} 4=1: 40, \mathrm{~A} 5=$ $1: 50$ ) and five solvents (water, acetic acid, hydrochloric acid, sodium hydro-xide) were used. On the basis of K/S values, the best extraction parameters were determined

Optimization of dyeing conditions: After extraction, effects of dyeing parameters such as dye concentration temperature, $\mathrm{pH}$, time and salt concentration were noted for process optimization. For optimizing the dyeing conditions, like different dyeing $\mathrm{pH}(2,4,6,8,10,12)$, dye concentration (25, $30,35,40,45,50)$, temperature $\left(40,50,60,70,80,90{ }^{\circ} \mathrm{C}\right)$, time $(20,40,60,80,100,120 \mathrm{~min})$ and salt concentration $(0$, $2,4,6,8,10 \mathrm{~g} / \mathrm{L}$ ) were carried out to find optimized dyeing condition. After dyeing, the dyed samples are rinsed with cold water and washed in a bath with a liquor ratio of 1: 50 using 1 $\mathrm{g} / \mathrm{L}$ of the soaping agent at $60{ }^{\circ} \mathrm{C}$ for $10 \mathrm{~min}$ and then they are rinsed and finally dried in a dryer.

Post-mordanting: To study the effect of post-mordanting, samples of cotton fabric were subjected to post-mordanting (after dyeing) with three mordants (M1 = alum, M2 = zinc sulphate and M3 = manganese sulphate) at different concentration with $1,2,3,4$ and $5 \%$ o.w.f, for $60 \mathrm{~min}$ at $60^{\circ} \mathrm{C}$ with L:R of 15:1. After the end of the process, the dyed fabrics were rinsed with distilled water.

Colour yield of dyed fabrics: The colour intensity of the dyed samples in the visible region of the spectrum (400-700 $\mathrm{nm}$ ) was expressed as the K/S values and calculated based on the Kubelka-Munk equation [17]:

$$
\frac{\mathrm{K}}{\mathrm{S}}=\frac{(1-\mathrm{R})^{2}}{2 \mathrm{R}}
$$

where $\mathrm{K}$ is the absorption coeffient, $(\mathrm{R})$ is the decimal fraction of dyed sample and $(\mathrm{S})$ is the light scattering coeffient.

Fastness testing: The colour fastness to washing, light and rubbing of the samples were determined according to ISO 105-CO6 A1S: 1994, ISO 105-B02: 1994 and ISO 105- X12: 2001, respectively.

Characterization: A GBC UV/VIS 916 (Australia) spectrophotometer and a Datacolor 3890 were employed for the absorbance. The functional groups of samples were determined with a Bruker (Tensor 27, Bruker Optics, Germany) Fourier transform infrared spectrophotometer (FT-IR) in the range $4000-400 \mathrm{~cm}^{-1}$. Fiber morphology characterized by A Hitachi
S-3700N Scanning electron microscope (SEM). Samples were mounted in aluminium holders with double-sided adhesive carbon tape and coated with an $\mathrm{Au}-\mathrm{Pd}$ layer.

\section{RESULTS AND DISCUSSION}

Optimization of extraction conditions: The type of solvent acclimated in the extraction process is major. Recently, altered types of organic solvents accept been acclimated to extract natural dyes from altered locations of the plant. The form of solvent affects the absorption spectrum of the dyes as well because the bonding between the dyes and the material surface [18]. Five solvents, namely, water, acetic acid, hydrochloric acid, sodium hydroxide and potassium hydroxide were acclimated to extract natural dyes from Macadamia integrifolia. As can be apparent from the Fig. 1(a), colour strength of dye extracts acquired in distilled water is not appreciable. It gets better with sodium hydroxide due to the phenolic and acidic hydroxyl accumulation in the lignin structure of colouring component, which reacts with alkali and form salt which is more soluble in water. Also sodium hydroxide can be associated to the negative electric charges created on the macademia nut surface. The electrostatic repulsion between the negative surface charge and the phenolate anions could be amenable for the acceptable after-effects acquired application $\mathrm{NaOH}$ solution $[19,20]$. Beside that cell wall is also made up of cellulosic material that gains anionic charge in alkaline medium. Because of these anionic repulsive forces among cell wall, it loses its strength and broken easily in alkaline medium. Thus the extraction of colouring component becomes more in alkaline medium. The effect of extraction temperature on the relative colour strength (K/S) values is accustomed in Fig. 1(b). There is accepted trend of acceleration in colour strength value with accretion temperature for extraction. Here, it was, appropriately set at $30,40,50,60$ and $70{ }^{\circ} \mathrm{C}$ to appraise the access of altered temperatures on the yield of the alcoholic extraction and it is acutely apparent that the colour strength value gradually with the increase of temperature and again accomplished the peak at $60{ }^{\circ} \mathrm{C}$ and decreased at $70{ }^{\circ} \mathrm{C}$. The access of extraction temperature from 30 to $60{ }^{\circ} \mathrm{C}$ promotes the dissolution of macademia nut colourant and heat renders the cell walls permeable, decreases the viscosity of the solvent, thus facilitates its better solubility of colour component [21]. The effect of extraction time on the colour strength values of macademia extracts is given in Fig. 1(c). As can be observed, the colour strength increases with increase in extraction time and reaches maximum value at $60 \mathrm{~min}$. A further increase in time results in decrease in colour strength. The effect of the extraction time can be correlated with the higher contact time of solvent with powder which grasped more colouring components into solution but further increase resulted in decrease of the colour yield which might be due to decomposition of colouring components at higher temperature with more contact time [22]. Fig. 1(d) represents the effect of extraction material-to-liquor ratio on colour strength values. Sample A2 showed the maximum colour strength value and then further increase in liquor ratio decrease the colour strength due to the congested behaviour of dye molecules, which increases the affinity of dye molecules for each other and hence reduce K/S. The optimum extraction 

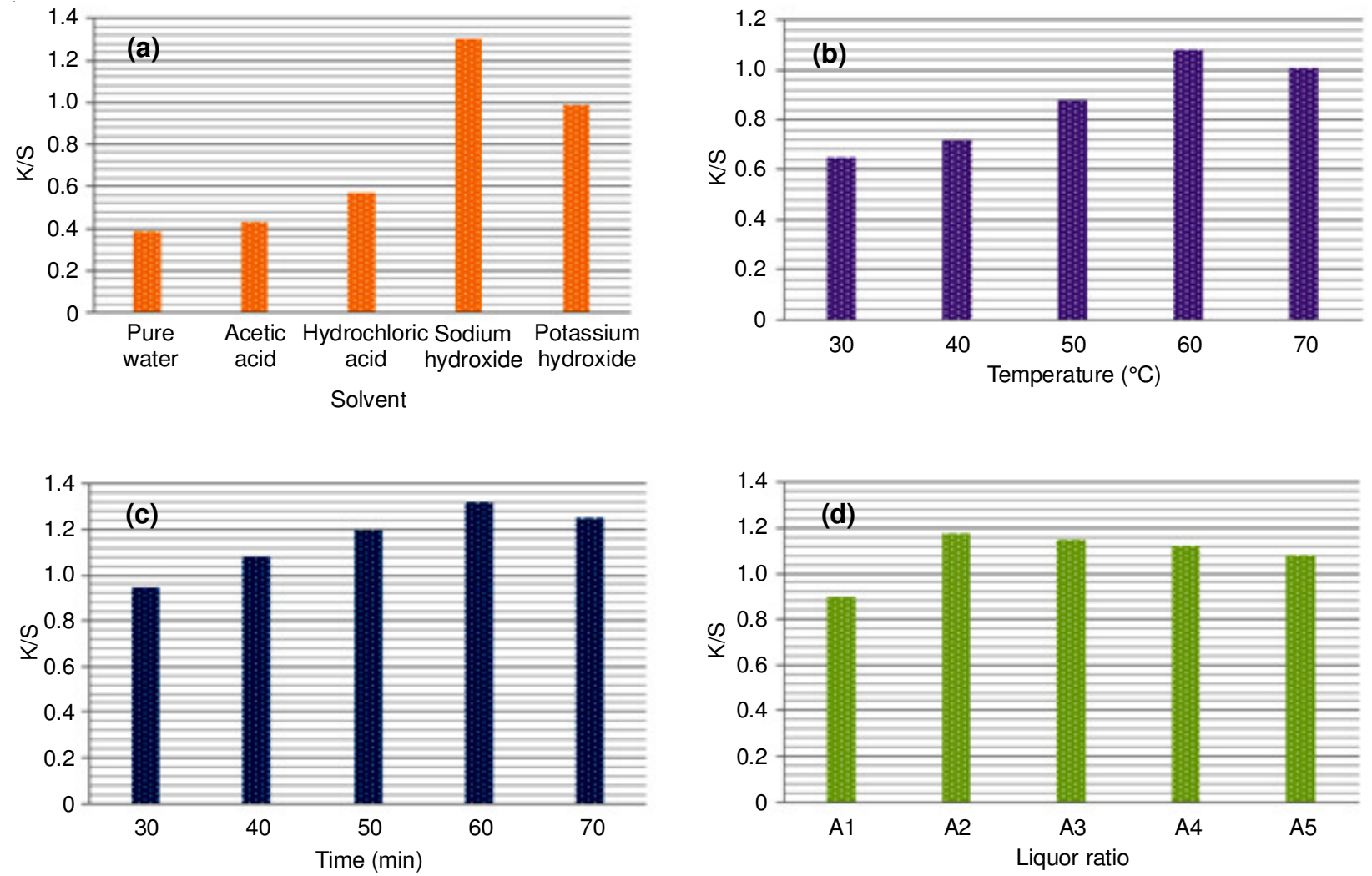

Fig. 1. Effect of extraction conditions on K/S value

conditions were found to be sodium hydroxide as solvent, $60{ }^{\circ} \mathrm{C}$ for temperature, $60 \mathrm{~min}$ for time factor and A2 (1:20) for material-to-liquor ratio.

Characterization of extracted dye: Fig. 2(a) represents UV-visible spectrum of macademia nut extract at a wavelength range of 200 to $500 \mathrm{~nm}$. Two above bands were recorded at 280 and $320 \mathrm{~nm}$. The aftereffect of UV-visible spectroscopic assay confirms the presence of lignin in the alcoholic extract of macademia. The peaks at about $280 \mathrm{~nm}$ is attributed to the absorbance of benzene rings in lignin, which is ascribed to the $\pi \rightarrow \pi^{*}$ transition and vibrational effect of benzene rings in

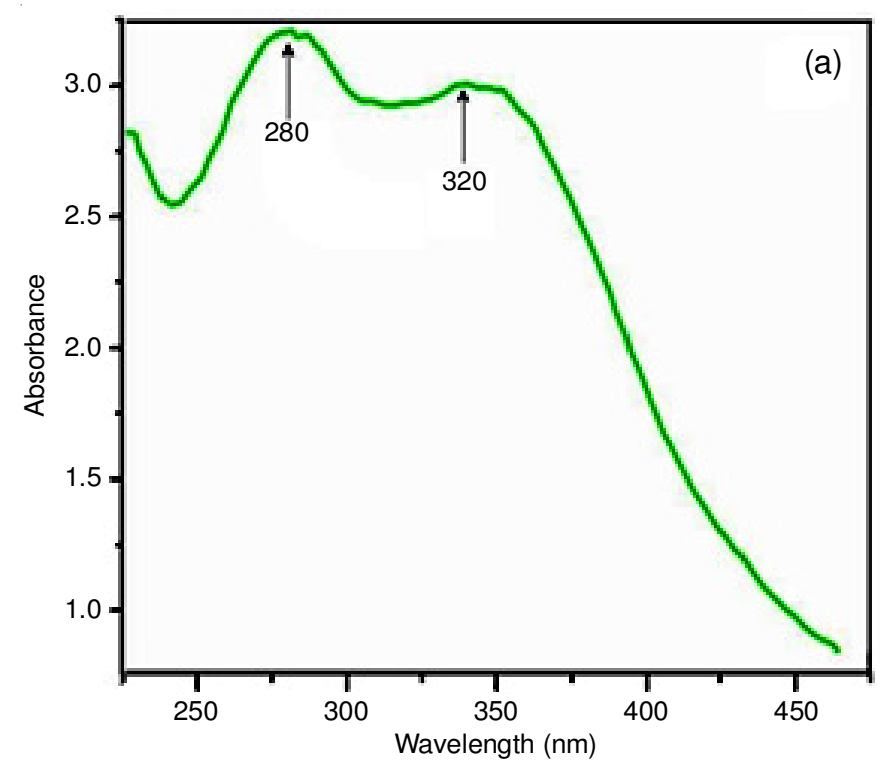

lignin [23,24]. Fig. 2(b) represents the FT-IR spectra of the pure alkali soluble lignin extracted form macadamia nutshell. The absorption at $1700 \mathrm{~cm}^{-1}$ is typical of hemicellulose, an impurity mixed in lignin and can be attributed to nonconjugated carbonyl groups due to alkali extraction [25]. The peak at 1656 $\mathrm{cm}^{-1}$ is attributed to the absorbance of $\mathrm{C}=\mathrm{C}$ stretching vibrations in the benzene ring of lignin. Aromatic ring vibrations are assigned at 1600, 1510 and $1424 \mathrm{~cm}^{-1}$. Absorption at 1464 $\mathrm{cm}^{-1}$ is indicative of $\mathrm{C}-\mathrm{H}$ deformations and aromatic ring vibrations. The presence of phenolic $\mathrm{OH}$ groups is shown by absorption bands at $1362 \mathrm{~cm}^{-1}$, whereas the one at $1030 \mathrm{~cm}^{-1}$

Fig. 2. (a) UV-visible spectrum and (b) FT-IR analysis for macademia nut extract 
is related to primary alcohols. The acce-lerated bands at 1230 and $845 \mathrm{~cm}^{-1}$ are assigned to the syringyl units, while small shoulders at 1265 and $1125 \mathrm{~cm}^{-1}$ can be attributed to the guaiacyl units [26].

Optimization of dyeing condition: The effects of dyeing temperature, time, $\mathrm{pH}$, dye concentration and salt concentration during dyeing of cotton fabric with the macademia nut extract on colour strength (K/S values) are illustrated in Fig. 3. Temperature of dyeing bath is one of the important ambits of textile processing. It is evident that the colour strength increased slowly with an increase in dyeing temperature from 40 to $80{ }^{\circ} \mathrm{C}$ (Fig 3(a)). Clearly, higher K/S value was empiric at $85^{\circ} \mathrm{C}$. Dyeing of textiles occurs mainly by adsorption of dye molecules over the apparent and temperature highly affects the adsorption by adsorption-desorption equilibrium. Temperatures at about $90^{\circ} \mathrm{C}$ shift the adsorption-desorption equilibrium adjoin appropriate and so the dye exhaustion decreases with the increase in dyeing temperature further [27]. Moreover, the decrease in colour strength at higher temperature was due to the desorption of colourant from the fabric to the dye bath while dyeing at low temperature caused incomplete sorption of colourant on the fabric [28]. The dyeing time is an acute constant in the action of dyeing. It is showed from the Fig. 3(b) that colour strength increases as the time of dyeing increase. This could be due to shift in equilibrium of colourant from fabric to dye bath. In view of $\mathrm{pH}$ values from Fig. 3(c), it can be seen that the fabric exhibited maximum colour strength at $\mathrm{pH} 8$ and then a plateau appeared after $\mathrm{pH} 8$ on the dyeing curve. At $\mathrm{pH}$ values lower than 6 , the extracted natural dyes have low solubility because of the ionization, which bound their dyeing performance. At a higher $\mathrm{pH}$ value than 8 , the conjugate structure of the natural dyes might be destroyed because of the oxidation, thus resulting in lower colour strength of the dyed cotton fabric [29]. In adjustment to appraise the aftereffect of concentration of dye on colour strength is shown
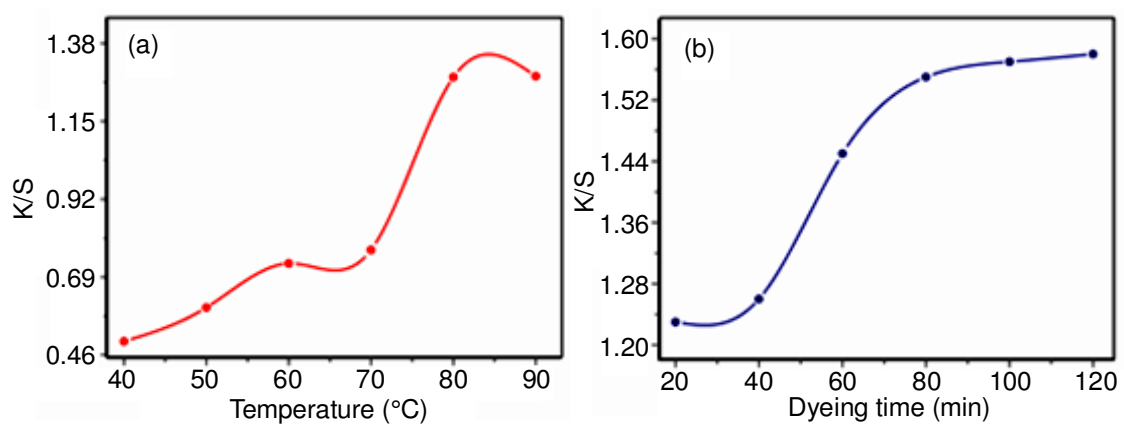

in Fig. 3(d). With the increase in dye concentration, an increase in colour strength $(\mathrm{K} / \mathrm{S})$ is empiric consistent in deeper shades having maximum colour depth with an increase in the dye adsorption. In Fig. 3(e), K/S value is plotted against varying salt concentration. Dye uptake in agreement of apparent colour strength increases with the increase in salt concentration in the dye-bath in each case and attains almost saturation at 10 $\mathrm{g} / \mathrm{L}$ of sodium chloride, which can be attributed to neutralization of negative charge due to zeta potential of cotton by sodium ions in the dye bath [30].

Effect of post-mordanting on colour strength: Fig. 4 represents colour strength $(\mathrm{K} / \mathrm{S})$ values for post-mordanting method on dyed fabric. Among five different concentrations $(1,2,3,4,5 \%$ owf) for post-mordanting, the highest colour strength is acquired with $3 \%$ (owf). This low colour strength at higher concentration of mordants can be outlined that the formations of the coordination bonds between the macademia dye and cellulose with metal cations of mordant as the central ions [31]. Metal mordants especially $d$-block elements have coordination complex forming ability and therefore readily chelate with the dye molecules forming ternary complexes eventually finally leading to larger colour strength values [32,33]. The mordant activity sequence was found to be M1 > M3 > M2.

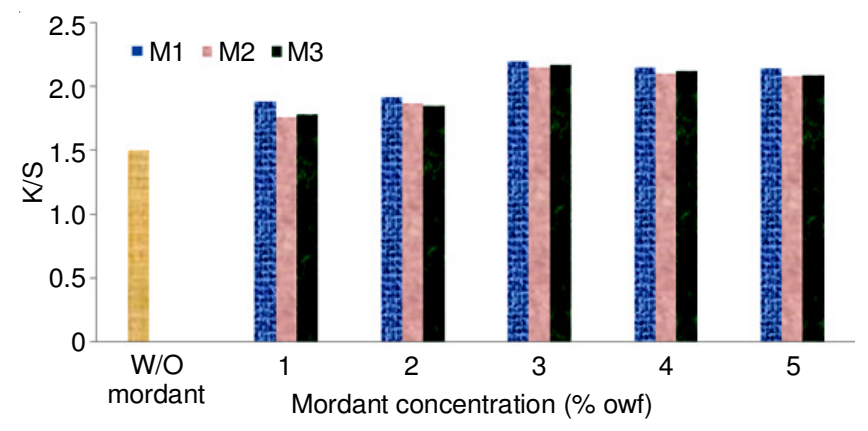

Fig. 4. Effect of post-mordanting on the colour strength (K/S)

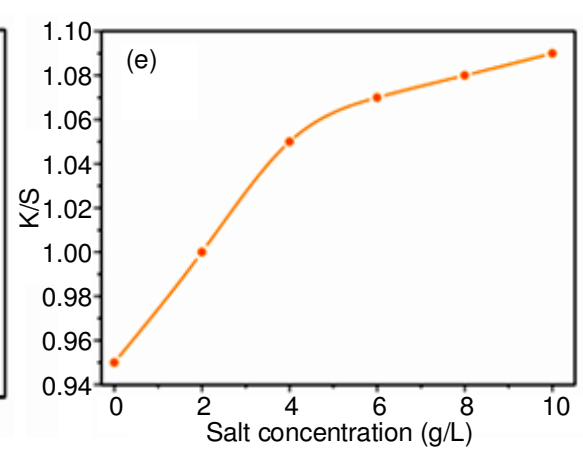

Fig. 3. Effect of dyeing conditions on K/S value 
Fastness properties: The rating results of colour fastness given in Table-1 showed that these properties have been improved by mordanting followed by dyeing at optimum conditions. The colour fastness is determined by the end use of the fabrics. The retention of the dye by the fabrics when exposed to different tests recorded good to excellent and excellent grades, indicating efficient retention. From the results it is observed that the post-mordant fabrics show good fastness when compared to control sample (without mordant). Wash fastness of the dye is influenced by the rate of diffusion of the dye and its state inside the fiber [34]. There was a relation between the nature of the dye mordant and dye removal under the influence of soap solution during washing. This depends on the groups capable to forming metal complex using mordant but unmordanted dyed sample also showed satisfactory grades due to the yarn which binds the affinity of the colouring components in the form of $\mathrm{H}$ bonding, ionic bonding and van der Waals forces $[35,36]$. The light fastness of samples shows very good fastness value in post-mordanting process. The light fastness of the dyed fabric decreases when their particle size decreases that are due to the greater specific surface of dyed particles exposed to light. The increase in light fastness of fabrics could be due to the decreasing surface activity of the dye molecules and the increased dye-fibre bond. The rubbing process leads to removal of dyed molecules adhered on to the surface of the fibre. But those forming intermolecular hydrogen bonding or forming metal complexation with the mordant are not removed by rubbing. The post-mordanted fabrics showed better rubbing fastness as they lead to better bonding with the mordant that without mordant [37].

TABLE-1

VALUES OF COLOUR FASTNESS OF SAMPLES

\begin{tabular}{ccccc}
\hline Samples & WF & LF & Dry RF & Wet RF \\
\hline Without mordant & 4 & 3 & $4 / 5$ & $3-4$ \\
M1 & 5 & 5 & 5 & 5 \\
M2 & $4 / 5$ & 4 & 5 & 5 \\
M3 & $4 / 5$ & 5 & $4 / 5$ & 5 \\
\hline
\end{tabular}

$\mathrm{WF}=$ wash fastness, $\mathrm{LF}=$ light fastness, $\mathrm{RF}=$ rubbing fastness

Chemical composition analysis: In the spectrum of Fig. 5(a) suggests the typical aspects of cellulose: a strong peak at $3418 \mathrm{~cm}^{-1}$ due to $\mathrm{O}-\mathrm{H}$ stretching, a peak at $2,900 \mathrm{~cm}^{-1}$ due to $\mathrm{C}-\mathrm{H}$ stretching and a broad absorption peak between 1,164 and $1,058 \mathrm{~cm}^{-1}$ which results from the contribution of more than a few functional groups, particularly $\mathrm{C}-\mathrm{C}$ stretching, $\mathrm{C}-\mathrm{O}$ stretching and $\mathrm{C}-\mathrm{O}-\mathrm{C}$ stretching [38]. The small peak at $1,642 \mathrm{~cm}^{-1}$ is due to partial oxidation of alcohol to carbonyl functional groups. Compared to undyed cotton's FT-IR spectrum, the dyed cotton FT-IR spectra Fig. 5(b) confirmed a top shift from $1,643.36 \mathrm{~cm}^{-1}$ to between $1,630 \mathrm{~cm}^{-1}$ and $1,671.90$ $\mathrm{cm}^{-1}$ due to mordanting procedure. Other than the peak shift at $1,643.36 \mathrm{~cm}^{-1}$, little chemical structure change took place in cotton during any dyeing procedure, suggesting macademia dye forms minimal chemical bonds with cotton fabric. Colour fastness was once accelerated by way of mordants after the dyeing process. However, the mordant had no credible after effect on the FT-IR spectra.
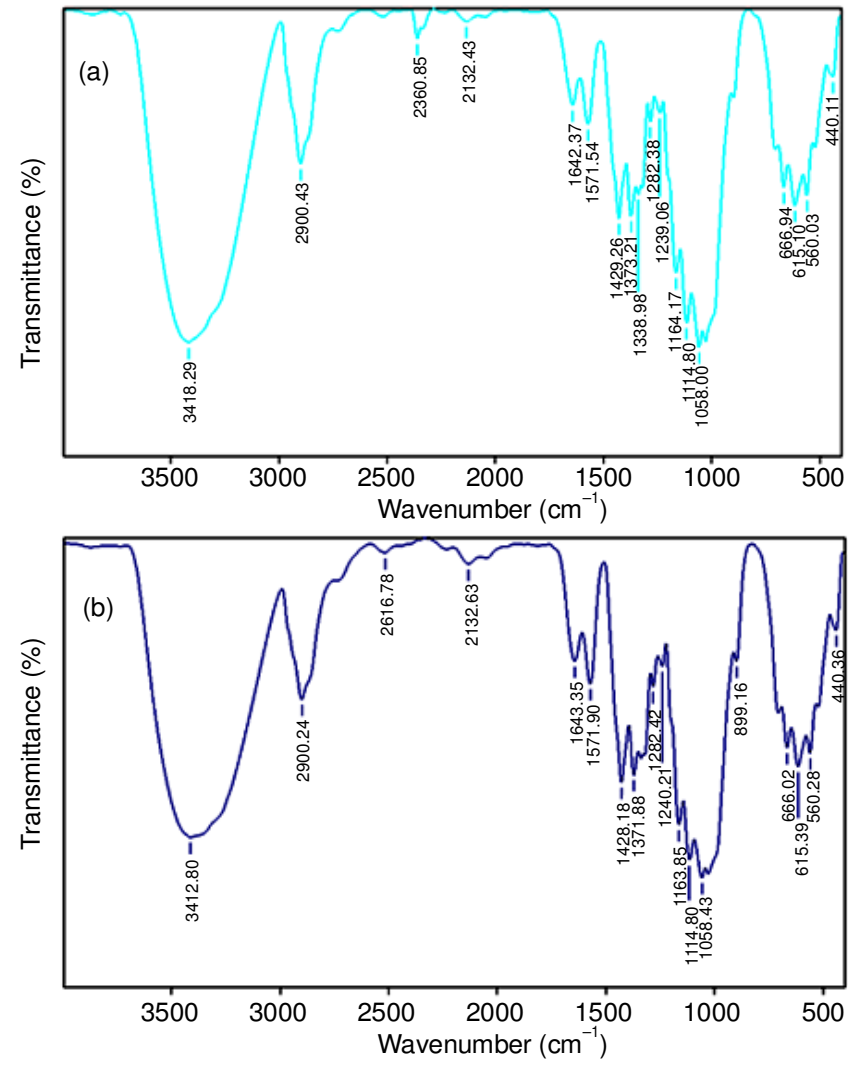

Fig. 5. FT-IR spectra of (a) Undyed and (b) dyed fabric

Fibre morphology: The figure of the cotton fibers before and after dyeing are shown in Fig. 6(a) and 6(b), respectively and both of the fibers are wrinkled. It can be observed from that the dyeing the fabrics with macademia does not affect the morphology. Fig. 6(c)-(d) represents the surface of postmordanted fibers that have been visible with no physical changes such as cracks on surface, responsible for alteration cotton fiber properties.

\section{Conclusion}

The analysis was acclimatized to implement an ecology affable natural dyeing process of cotton using macademia nutshell dye as a new source for textile colouration. The process parameters, extraction, dyeing and post-mordanting conditions varied and the results were optimized and the enhancement in the colour strength was correlated with an increase in the mentioned procedure. Lignin was found on macademia nut extracted solution for the first time in this work and it increase the present knowledge of the natural variability of wood and bark lignins and stress their importance, e.g., for conversion and valorization approaches in biorefinery platforms. The address and insights of the present study will accord to the dyeing of fabrics application assorted natural dyes. The useful properties of natural dyes reported in this study will animate others to acquisition for the typical advantages of abounding added plants.

\section{ACKNOWLEDGEMENTS}

The authors would like to express our gratitude towards Prof. Quan Heng (Vice Dean, School of Chemistry \& Chemical Engineering at Wuhan Textile University) for his constant 


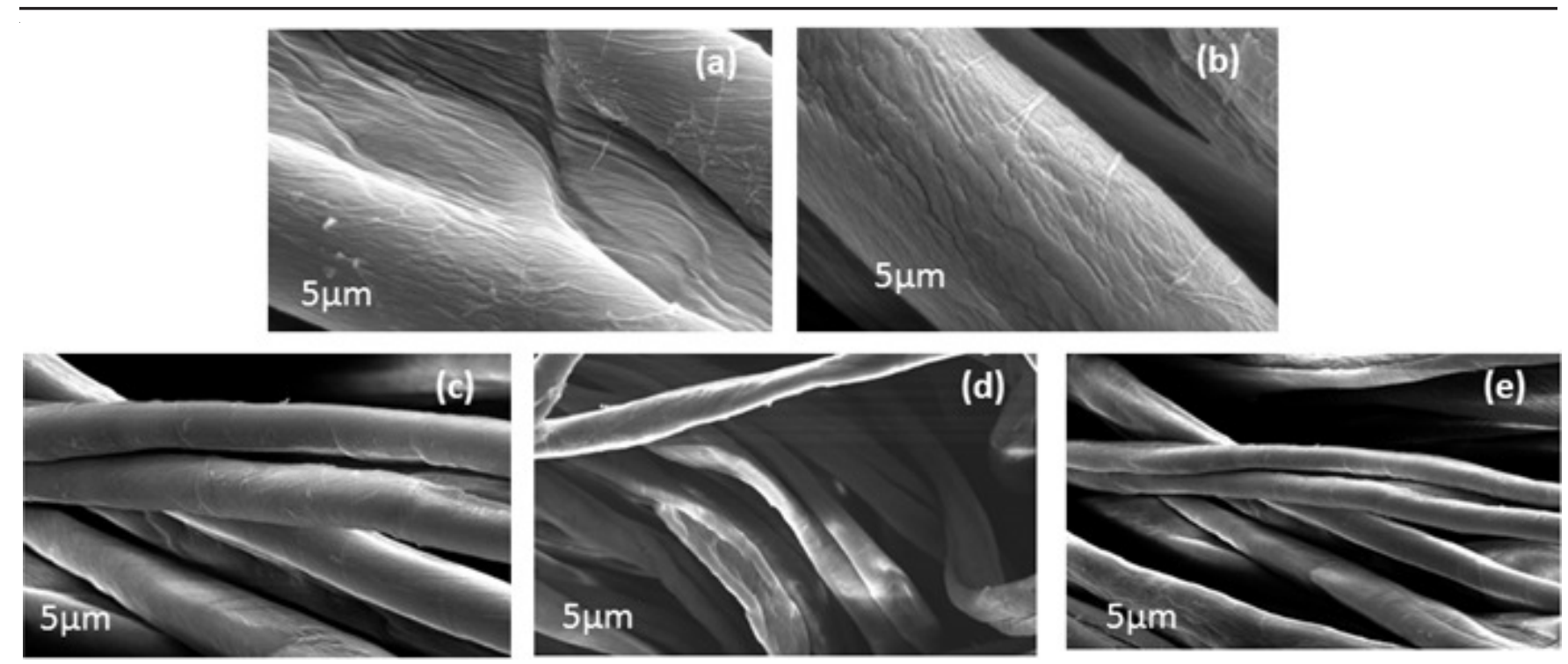

Fig. 6. SEM pictures of (a) undyed, (b) dyed and post-mordanted (c) M1, (d) M2 and (e) M3

guidance, advice and encouragement throughout this research. Also, we would like to thank Runhe Chemical Industry \& Color Root (Hubei) Technology Limited, China, for providing the financial support.

\section{REFERENCES}

1. A.K. Samantaa and P. Agarwal, Indian J. Fibre Text. Res., 34, 384 (2009).

2. T. Bechtold, A. Mahmud-Ali and R. Mussak, Dyes Pigments, 75, 287 (2007); https://doi.org/10.1016/j.dyepig.2006.06.004

3. S.-i. Eorn, D.-y. Shin and K.-j. Yoon, Indian J. Fibre Text. Res., 26, 425 (2001).

4. M.N. Pervez and M.A. Rahman, Int. J. Sci. Eng. Res., 6, 660 (2015).

5. P.S. Vankar and R. Shanker, Desalination, 230, 62 (2008); https://doi.org/10.1016/j.desal.2007.11.016.

6. D. Grifoni, L. Bacci, S. Di Lonardo, P. Pinelli, A. Scardigli, F. Camilli, F. Sabatini, G. Zipoli and A. Romani, Dyes Pigments, 105, 89 (2014); https://doi.org/10.1016/j.dyepig.2014.01.027.

7. B. Zhang, L. Wang, L. Luo and M.W. King, J. Clean. Prod., 80, 204 (2014); https://doi.org/10.1016/j.jclepro.2014.05.100

8. D.B. Gupta and M.L. Gulrajani, Indian J. Fibre Sci. Technol., 18, 202 (1993).

9. M.L. Garg, R.J. Blake and R.B. Wills, J. Nutr., 133, 1060 (2003)

10. A. Wechsler, et al., Proceedings of the 18th International Conferences on Composite Materials (ICCM), Jeju Island, Korea (2011).

11. N. Ibrahim, A.R. El-Gamal, M. Gouda and F. Mahrous, Carbohydr. Polym., 82, 1205 (2010); https://doi.org/10.1016/j.carbpol.2010.06.054.

12. S. Ali, T. Hussain and R. Nawaz, J. Clean. Prod., 17, 61 (2009); https://doi.org/10.1016/j.jclepro.2008.03.002.

13. I.A. Bhatti, S. Adeel, M.A. Jamal, M. Safdar and M. Abbas, Radiat. Phys. Chem., 79, 622 (2010); https://doi.org/10.1016/j.radphyschem.2009.12.006.

14. A. Popoola, J. Appl. Polym. Sci., 77, 752 (2000); https://doi.org/10.1002/(SICI)1097-4628(20000725)77:4<752::AIDAPP6>3.0.CO;2-C

15. S. Kim, Fibers Polym., 7, 255 (2006); https://doi.org/10.1007/BF02875682.

16. N. Verma, N. Gupta, and S. Parthsarthy, Indian Textile J., 108, 82 (1998).

17. P. Kubelka, J. Optical Soc. Am., 38, 448 (1948); https://doi.org/10.1364/JOSA.38.000448.

18. M.A. Al-Alwani, A.B. Mohamad, A.A.H. Kadhum and N.A. Ludin, Spectrochim. Acta A Mol. Biomol. Spectrosc., 138, 130 (2015); https://doi.org/10.1016/j.saa.2014.11.018.
19. L. Quinn and H. Tang, J. Am. Oil Chem. Soc., 73, 1585 (1996); https://doi.org/10.1007/BF02523529.

20. L.A. Rodrigues, L.A. de Sousa Ribeiro, G.P. Thim, R.R. Ferreira, M.O. Alvarez-Mendez and A.R. Coutinho, J. Porous Mater, 20, 619 (2013); https://doi.org/10.1007/s10934-012-9635-5

21. P. Tan, C.P. Tan and C.W. Ho, Int. Food Res. J., 18, 557 (2011).

22. F. Nagia and R. El-Mohamedy, Dyes Pigments, 75, 550 (2007); https://doi.org/10.1016/i.dyepig.2006.07.002.

23. T. Todorciuc, A.-M. Capraru, I. Kratochvílová and V.I. Popa, Cellulose Chem. Technol., 43, 399 (2009).

24. Z. Wei, Y. Yang, R. Yang and C. Wang, Green Chem., 14, 3230 (2012); https://doi.org/10.1039/c2gc36278c.

25. L.M. Kline, D.G. Hayes, A.R. Womac and N. Labbé, BioResources, 5, 1366 (2010).

26. B. Hansen, P. Kusch, M. Schulze and B. Kamm, J. Polym. Environ., 24, 85 (2016); https://doi.org/10.1007/s10924-015-0746-3.

27. A. Ansari and B. Thakur, Colourage, 47, 15 (2000).

28. M. Shabbir, L.J. Rather, Shahid-ul-Islam, M.N. Bukhari, M. Shahid, M. Ali Khan and F. Mohammad, J. Adv. Res., 7, 473 (2016); https://doi.org/10.1016/j.jare.2016.03.006

29. C. Wang, C. Xu, A. Tian, S. Fu and C. Wang, Color. Technol., 129, 32 (2013); https://doi.org/10.1111/j.1478-4408.2012.00407.x.

30. V. Shenhnai, Technology of Textile Processing, vol. II, pp. 159-193 (1997).

31. S. Bhattacharya and A. Shah, Color. Technol., 116, 10 (2000); https://doi.org/10.1111/j.1478-4408.2000.tb00002.x.

32. S.A. Khan, A. Ahmad, M.I. Khan, M. Yusuf, M. Shahid, N. Manzoor and F. Mohammad, Dyes Pigments, 95, 206 (2012); https://doi.org/10.1016/j.dyepig.2012.04.010.

33. Shahid-ul-Islam, L.J. Rather, M. Shahid, M.A. Khan and F. Mohammad, Ind. Crops Prod., 59, 337 (2014); https://doi.org/10.1016/j.indcrop.2014.05.041

34. P.S. Vankar, Handbook on Natural Dyes for Industrial Applications National Institute of Industrial Research New Delhi, India (2013).

35. S.A. Khan, Shahid-ul-Islam, M. Shahid, M.I. Khan, M. Yusuf, L.J. Rather, M.A. Khan and F. Mohammad, J. Nat. Fibers, 12, 243 (2015); https://doi.org/10.1080/15440478.2014.919893.

36. M. Yusuf, M. Shahid, M.I. Khan, S.A. Khan, M.A. Khan and F. Mohammad, J. Saudi Chem. Soc., 19, 64 (2015); https://doi.org/10.1016/j.jscs.2011.12.020

37. P. Ganesan and T. Karthik, J. Textil. Inst., 108, 1173 (2017); https://doi.org/10.1080/00405000.2016.1222862.

38. A. Khan, M.N. Pervez, I.A. Khan, S. Ahmad, R. Masood, T. Hussain and F. Telegin, Asian J. Chem., 28, 1191 (2016); https://doi.org/10.14233/ajchem.2016.19612. 